\title{
Análise do perfil dos corredores e eventos de corridas de rua da cidade de Curitiba-PR
}

Analysis of the profile of the runners and events of running of the city of Curitiba-PR

\author{
Jeferson Roberto Rojo \\ Universidade Estadual de Maringá, Brasil \\ jeferson.rojo@hotmail.com \\ Francielli Ferreira da Rocha \\ Universidade Estadual de Maringá, Brasil \\ franciellirocha13@gmail.com
}

\section{Resumo:}

As corridas de rua estão cada vez mais em evidência no cenário esportivo brasileiro e diversos fatores os motivam a pratica desta modalidade. Este artigo tem o objetivo de analisar o perfil dos corredores e dos eventos de corrida de rua na cidade de Curitiba-PR. Foram utilizados como fontes planilhas de controle interno, relatórios e calendário oficial fornecidos pela Secretaria Municipal de Esporte, Lazer e Juventude (SMELJ). Os resultados demonstraram que a grande maioria dos corredores do circuito de corridas de rua de Curitiba é do sexo masculino, com predominância de idade entre 30 e 50 anos, foi possível ainda observar uma queda significativa na participação dos indivíduos cadeirantes e deficientes visuais nas corridas de rua de Curitiba. Concluímos que os dados encontrados nesse estudo apontam para características que sugerem a corrida de rua como sendo uma modalidade com praticantes com melhores condições financeiras e eventos denominados como corridas fashion.

PalaVras-chave: Perfil, Corrida de rua, Esporte.

\section{Abstract:}

Running events are increasingly evident in the Brazilian sports scene and several factors motivate people to practice it. This article aims to analyze the profile of the runners and running events in the city of Curitiba-PR. Internal control spreadsheets, reports and official calendar provided by the Municipal Secretariat of Sports, Leisure and Youth (SMELJ) were used as sources. The results showed that the great majority of the runners of Curitiba\&\#39;s running circuit are male, predominately between 30 and 50 years old. Moreover, it was possible to observe a significant decrease in the participation of wheelchair and visually impaired individuals in the running of Curitiba. We conclude that the data found in the study point to characteristics that suggest that running has practitioners with good economic position and its events are known as fashion running.

KeYwORDs: Profile, Running, Sport.

\section{INTRODUÇÃO}

As corridas de rua estão em evidencia no cenário esportivo brasileiro. Sendo que são diversos os fatores que motivam os praticantes a aderirem a modalidade (Balbinotti, Gonçalves, Klering, Wiethaeuper \& Balbinotti, 2015). Para além dos motivos de adesão a prática da corrida de rua, aproximando com o pensamento de estudiosos da sociologia do esporte, que seria entender o fenômeno como algo polissêmico (Marchi Jr, 2015), observa-se também que há a ampliação do perfil dos praticantes, como também os modelos de evento começam a se diversificar (Rojo, Starepravo, Canan, Mezzadri y Silva, 2017).

O fenômeno da ascensão do número de praticantes das corridas de rua, assim como ocorre pensando em um cenário brasileiro, também é observado quando refere-se a realidade curitibana. A ligação de Curitiba com a corrida de rua não é algo recente, relatos fornecidos por meio de fontes contam o início dessa relação. Segundo Moraes e Silva (2011), em meados de 1899 já haviam registros de corridas pedestres na cidade. Como afirmam as fontes utilizadas pelo autor: "Realiza-se amanhã em Piraquara uma importante corrida a pé, pela quantia de um conto de reis. Para aquela localidade já tem seguido muita gente” (Moraes E Silva, 2011, p. 140). 
Desta forma, o presente artigo tem o objetivo de analisar o perfil dos corredores e dos eventos de corrida de rua na cidade de Curitiba-PR. Debruçar-nos-emos sobre o diálogo com fatos de relevância histórica para universo das corridas de rua no município, bem como com os aspectos que compõem a estrutura existente acerca da modalidade em Curitiba.

\section{METODOLOGIA}

$\mathrm{O}$ artigo se caracteriza como qualitativo e descritivo, com intuito de analisar o perfil dos corredores e dos eventos de corrida de rua na cidade de Curitiba-PR. Foram utilizados como fontes planilhas de controle interno fornecidas pela Secretaria Municipal de Esporte, Lazer e Juventude (SMELJ), Relatórios veiculados em publicações da entidade, bem como, o CALENDÁRIO OFICIAL - CORRIDAS DE RUA, CICLISMO E CAMINHADA $2015^{1}$.

A presente pesquisa conta com a aprovação do comitê de ética da universidade, sob o parecer de número 47607114.8.0000.0102, como também foi aprovada pelo órgão competente vinculado a Prefeitura Municipal de Curitiba.

\section{RESULTADOS}

\section{O corredor curitibano}

Com o propósito de compreender o universo das corridas de rua em Curitiba, entendemos a necessidade de conhecer um dos principais atores dentro desse espaço social. Para isso, no presente tópico realizaremos uma descrição do perfil do corredor curitibano. Para atingir nossos objetivos, partimos de dados referentes aos participantes dos eventos promovidos pela SMELJ.

A primeira variável analisada é a distribuição dos participantes por sexo. Para observamos essa proporção, apresentamos o gráfico a seguir, com os números referentes ao período entre os anos de 2008 e 2014:

Gráfico 1: Distribuição de corredores por sexo ${ }^{2}$.

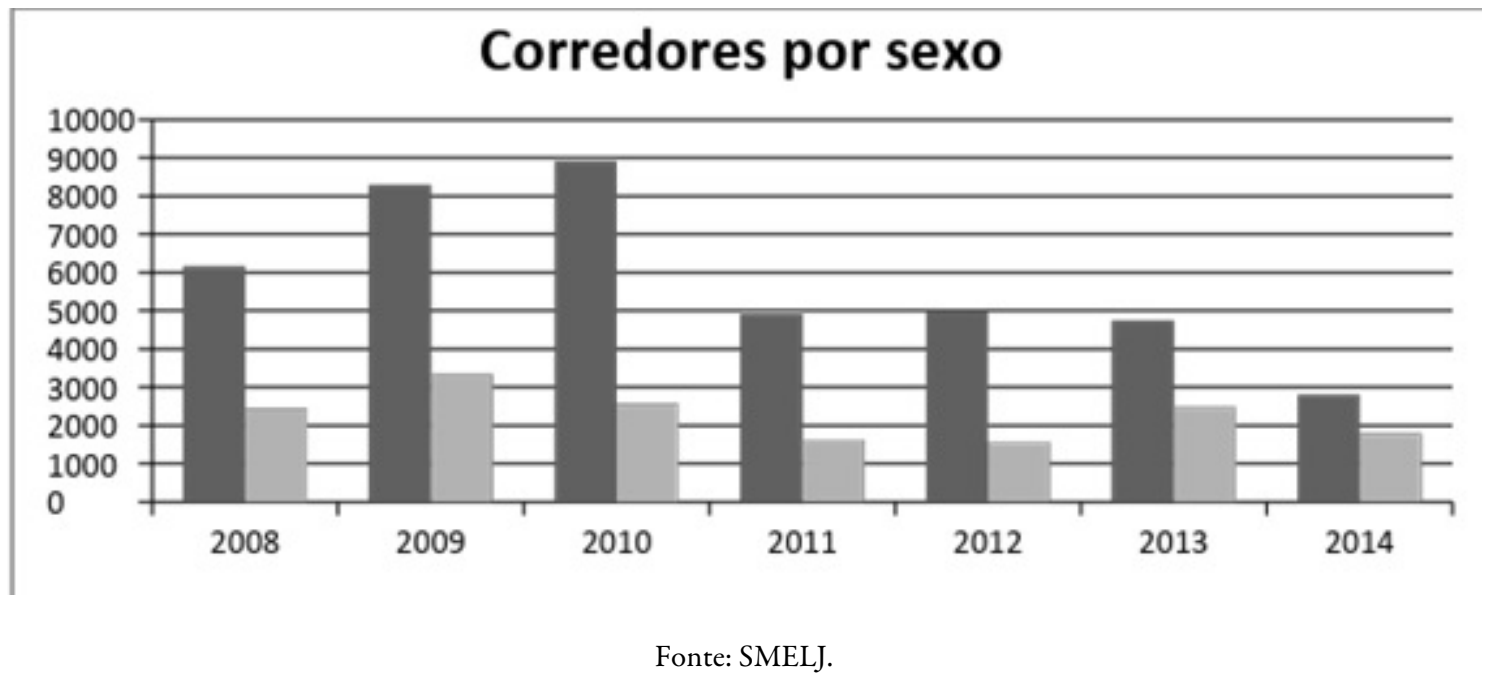

Como podemos observar no Gráfico 1, a grande maioria dos corredores do circuito de corridas de rua de Curitiba, dentro do recorte temporal, é do sexo masculino. No ano de 2008 o sexo feminino correspondia apenas a $28,52 \%$ da participação nos eventos analisados. Porém, se compararmos com os dados referentes ao 
ano de 2014, as corredoras representavam 38,85\% dos participantes. O sexo feminino aumenta mais de $10 \%$ e reduz a diferença proporcional entre os sexos nas corridas de rua.

A próxima variável a ser analisada é a faixa etária dos participantes das corridas de rua em Curitiba. $\mathrm{O}$ gráfico a seguir apresenta a variação da participação por faixa etária entre os anos de 2008 a 2014.

Gráfico 2: Distribuição dos participantes por faixa etária (Masculino)

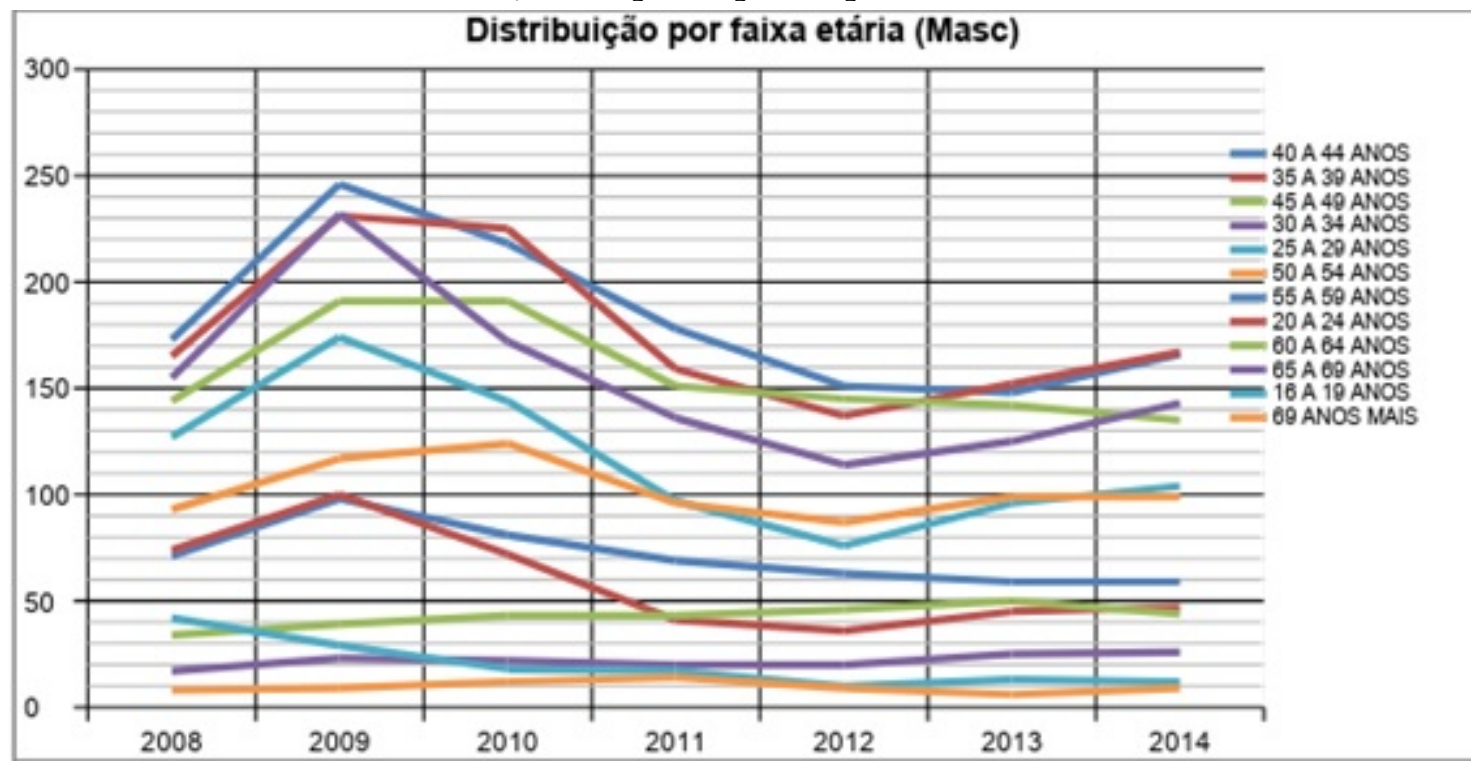

Fonte: SMELJ.

O Gráfico 2, apresenta a distribuição de participantes masculinos por faixa etária. Como podemos observar, todas as categorias de idade são representadas. Porém, tem-se uma predominância, em todo o período analisado, de atletas das 4 faixas etárias correspondentes à idade entre 30 e 50 anos. Já os índices de menor participação estão com as categorias extremas da análise, ou seja, os mais jovens (16 a 19 anos), e os mais idosos (69 anos a mais).

O cenário observado, quando nos referimos às participantes da categoria feminina, não se diferencia muito do encontrado no masculino. Tal fato pode ser observado no gráfico que apresentamos a seguir.

Gráfico 3: Distribuição dos participantes por faixa etária (Feminino).

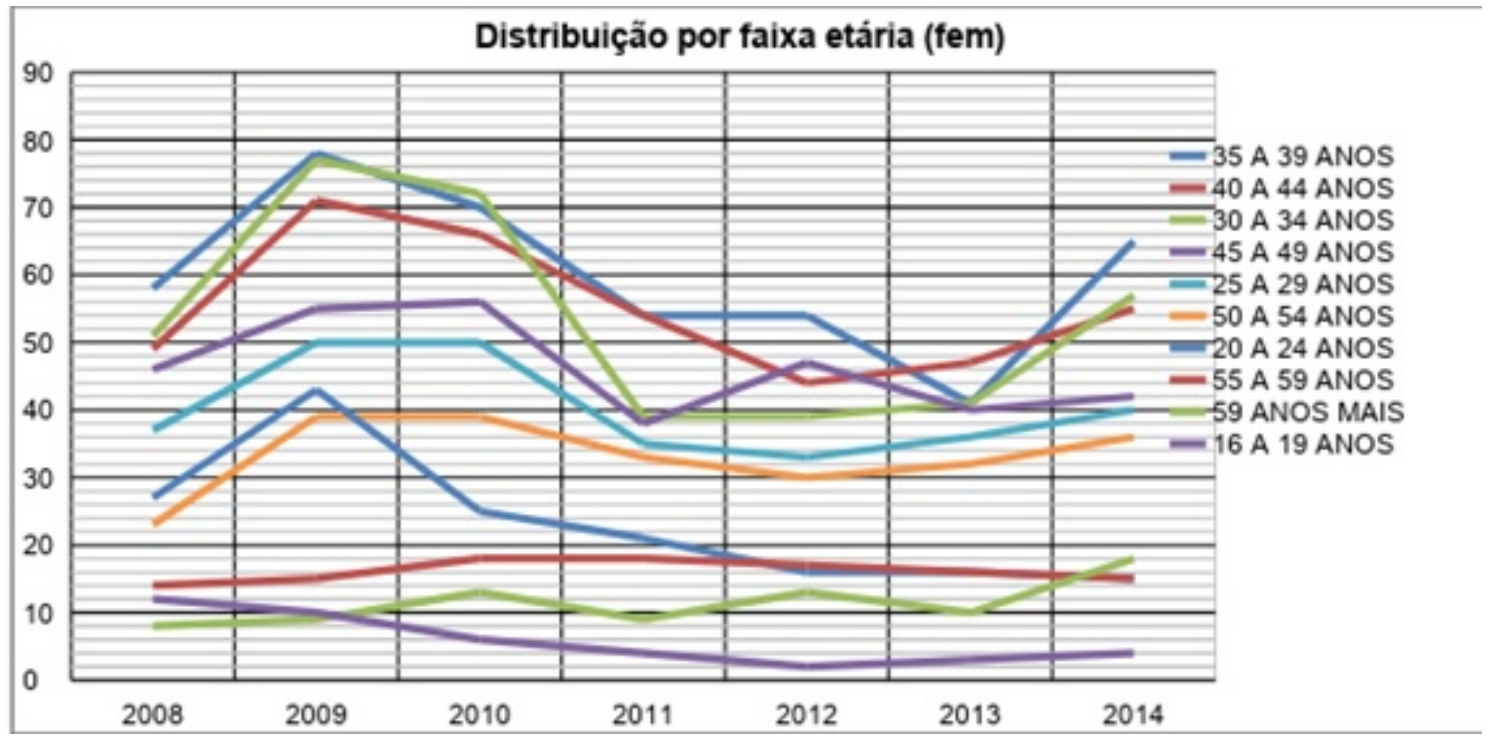


Fonte: SMELJ

No caso feminino, temos 3 categorias de idade que se destacam com a maior participação nas corridas. São elas as que contemplam corredoras com idade entre 30 a 44 anos. Em um panorama geral, se consideramos todo o período analisado, as categorias extremas do sexo feminino são as que possuem o menor volume de participação de atletas, sendo elas as faixas etárias de 16 a 19 anos e de 59 anos ou mais.

Outro aspecto de grande importância para as elaborações das políticas públicas, relacionado ao perfil do praticante da corrida de rua, é a participação do indivíduo com deficiência. O cenário dessa categoria será abordado a seguir no gráfico 4 .

Gráfico 4: Número de participantes cadeirantes.

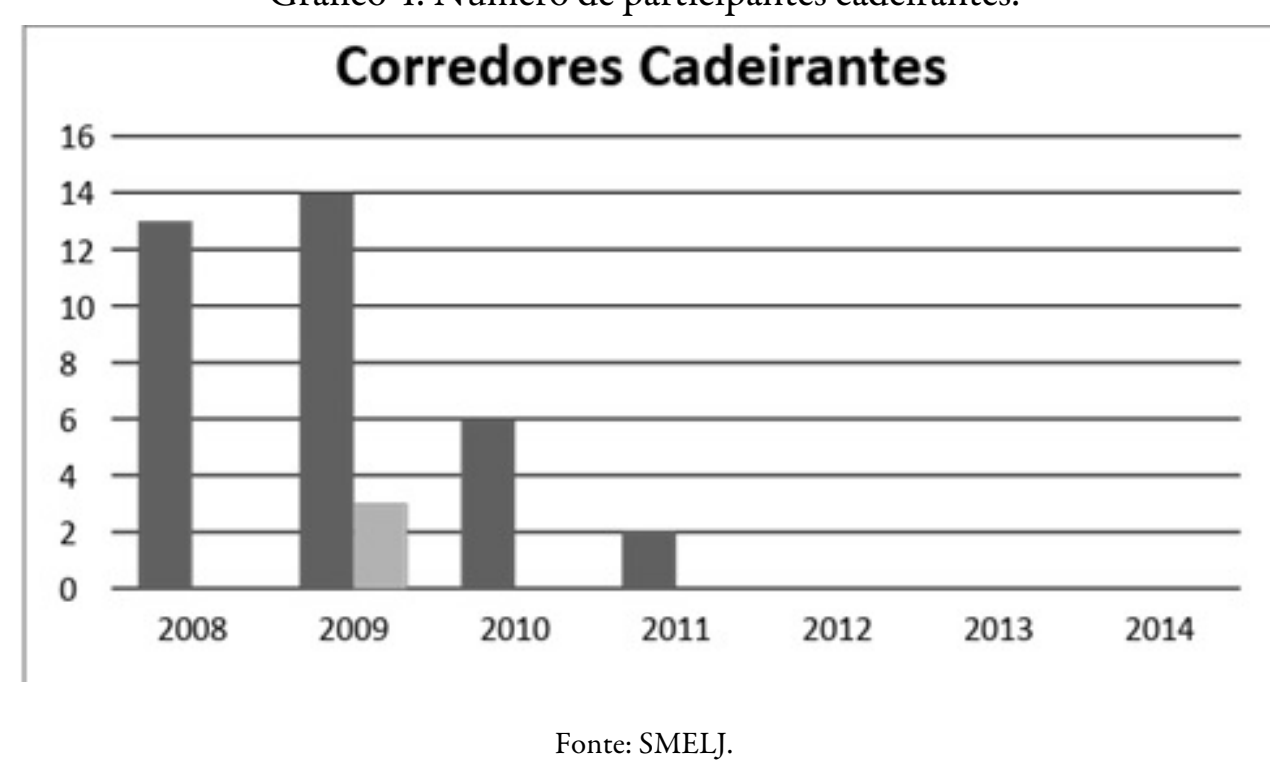

Como podemos observar no gráfico, quando a participação é do indivíduo utilizador de cadeiras de rodas, os números que já eram baixos chegaram à inexistência de participantes após o ano de 2012 para o sexo masculino. Já para a realidade do sexo feminino, apenas no ano de 2009 houve a participação de corredoras cadeirantes.

Os indivíduos com deficiência visual (DV) pertencem a outra categoria que participa de eventos de corrida de rua, como podemos observar no gráfico abaixo.

Gráfico 5: Número de participantes com Deficiência Visual.

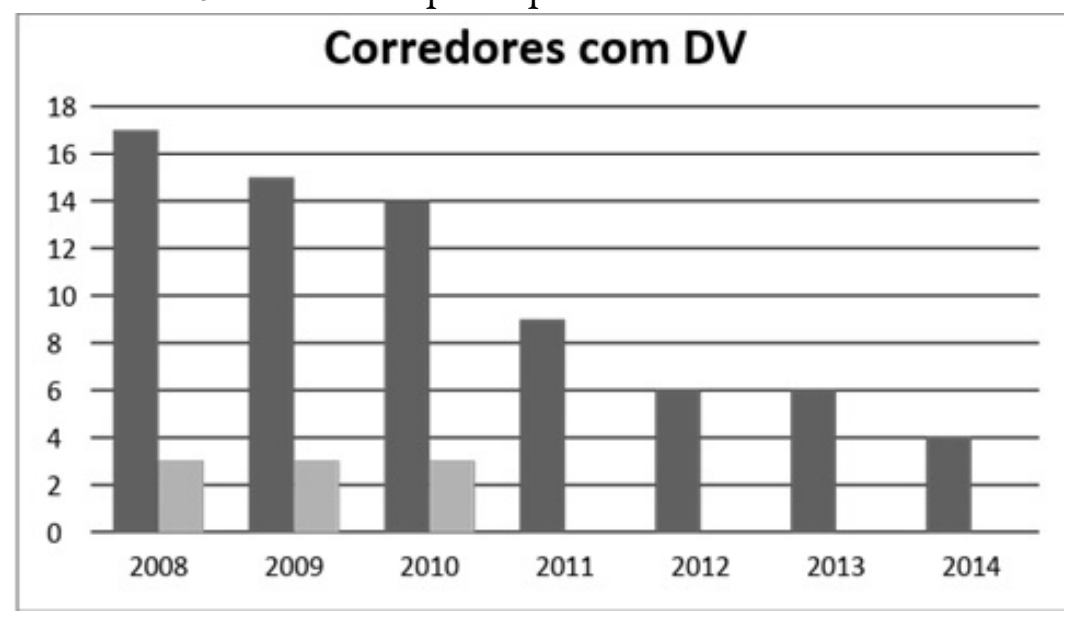

Fonte: SMELJ. 
O Gráfico 5, assim como no caso dos cadeirantes, revela uma queda significativa na participação dos indivíduos com DV nas corridas de rua de Curitiba. No sexo masculino, o número que em 2008 era de 17 corredores, caiu para 4 indivíduos em 2014. No feminino, nos três primeiros anos do recorte, participaram 3 corredoras, já posteriormente a 2011, não houve participantes.

\section{As corridas de Curitiba}

Os eventos de corrida de rua em Curitiba, como vimos, não foram realizados apenas recentemente. Assim como ocorreu em outros países, e em outras localidades do Brasil, é notado em Curitiba o crescimento do número desses eventos na cidade. Segundo Furlan (2014), no ano de 2011 foram realizadas 47 corridas na cidade de Curitiba, com um aumento para 65 eventos no ano de 2012. Os dados do Calendário Oficial de 2015 apontam que um número de 75 corridas ocorreu no ano.

Ao considerar esse contexto e todas as diferenças das naturezas dos eventos de corrida de rua, no presente tópico deste capítulo buscaremos descrever o cenário dos eventos das corridas de rua realizadas na cidade de Curitiba. Para atingir tal objetivo nos apoiamos no calendário oficial de 2015 de corridas de rua, ciclismo e caminhada, disponibilizado pela SMELJ.

A distribuição das modalidades (Corrida de rua, Ciclismo e Caminhada), é apresentada no Gráfico 6. É notável, que mesmo com a apresentação das outras duas modalidades, são predominantes os eventos de corrida de rua.

Gráfico 6: Modalidades do calendário oficial de 2015

\section{MODALIDADES}

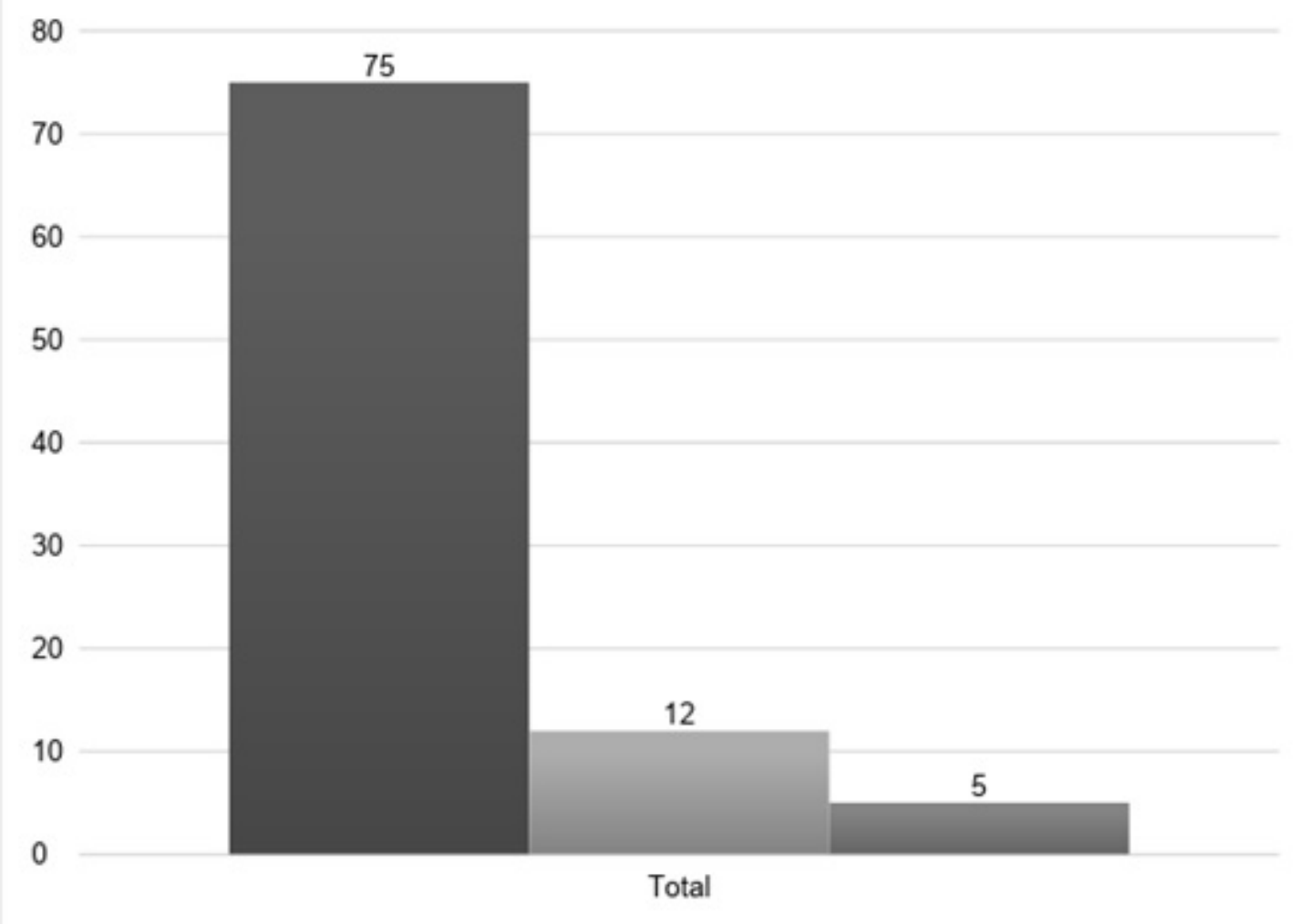

Fonte: Elaborado pelo autor com dados do Calendário Oficial de 2015 da SMELJ 
Como podemos observar a partir do Calendário Oficial de 2015, ocorreram 92 eventos no ano de 2015, sendo que 75 destes, que correspondem a $81.52 \%$ do total, são corridas de rua. O Ciclismo aparece posteriormente com 12 eventos no ano, que são 13.04\% do total. Já a caminhada soma 5 eventos realizados no ano de 2015, ou seja, 5.43\% de todos os eventos do calendário realizados na cidade de Curitiba.

Reconhecendo a importância e os impactos que a região metropolitana de Curitiba pode gerar na estrutura das corridas de rua na cidade de Curitiba, prosseguimos com as análises dos dados gerados a partir do Calendário Oficial de 2015. Ainda com o quadro de que as corridas de rua são realizadas durante todo o ano na cidade, observamos o Gráfico 7 que apresenta a distribuição dos eventos por meses.

Gráfico 7: Distribuição de corridas de rua por mês.

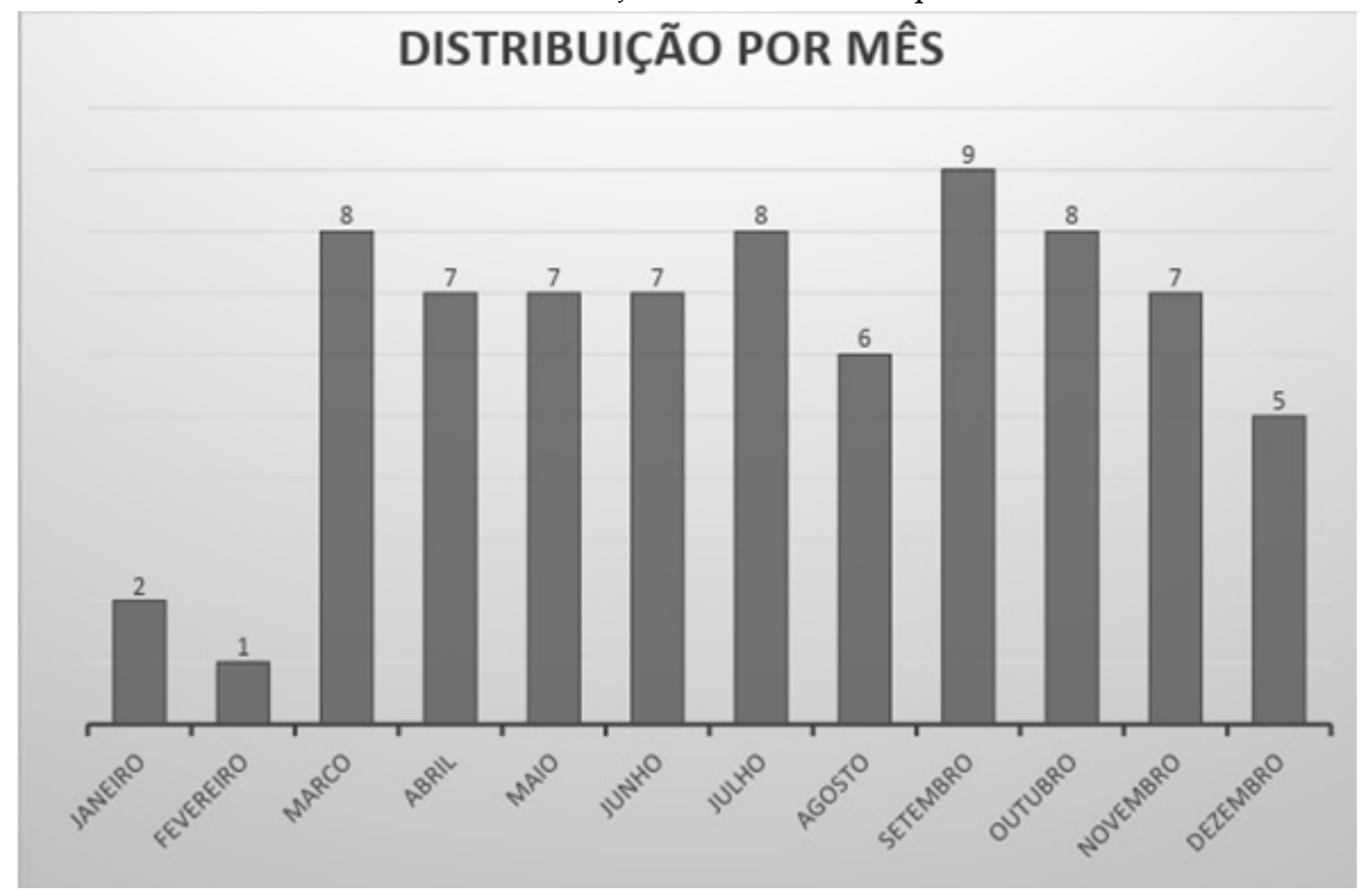

Fonte: Elaborado pelo autor com dados do Calendário Oficial de 2015.

Analisando o gráfico, percebemos que as provas são bem distribuídas ao longo do ano. Porém, os dois primeiros meses do ano, janeiro e fevereiro, são os meses com o menor número de provas registrado. Em janeiro duas corridas, e em fevereiro apenas um registro de evento.

A quantidade de eventos de corrida de rua em Curitiba, é realmente grande e corresponde, como vimos, a uma média maior do que um evento por semana, isso desconsiderando os possíveis eventos que ocorrem na região metropolitana. Porém, as responsabilidades pela organização desses eventos são diversas. Há corridas com características e objetivos diferentes como podemos observar no gráfico a seguir: 
Gráfico 8: Responsáveis pela organização das corridas de rua em Curitiba.

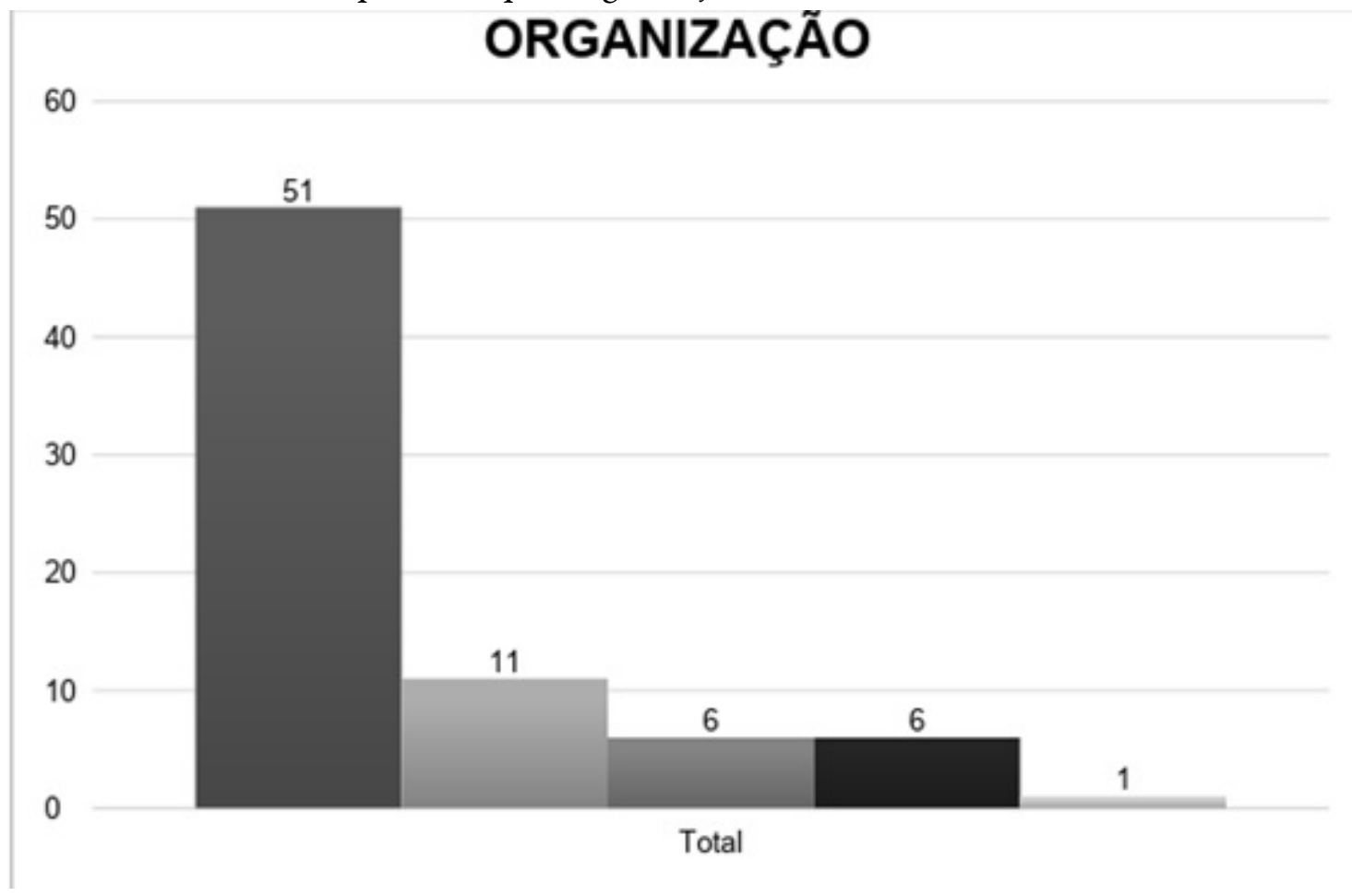

Fonte: Elaborado pelo autor com dados do Calendário Oficial de 2015

O Gráfico 8 retrata a distribuição do número de corrida de rua pelas características das entidades organizadoras do evento. Identificamos, por meio dos dados encontrados no Calendário Oficial de 2015, cinco perfis de organizadores de corridas de rua em Curitiba.

O perfil de organizador com o menor número de corridas realizadas é o que denominamos como parceria público/privada. Foi organizada uma única corrida com esse perfil de gestão. Posteriormente surgem os eventos organizados por entidades do Sistema S (SESC, SESI, SENAT...). As corridas organizadas por essas entidades somaram um número de seis, sendo que 4 destas são enquadradas dentro do circuito de corridas promovido pelo SESI para a cidade de Curitiba ${ }^{3}$.

Também com 6 corridas catalogadas, aparecem as provas organizadas, ou de tutela do que denominamos judiciário/policial/exército. Essas provas são realizadas por órgãos que fazem referência a esses setores, sendo que, em algumas delas há homenagem a datas ou situações com relação às práticas das entidades.As corridas organizadas pelo poder público somam 11 eventos. Esses eventos são realizados pela SMELJ, destinados a diversos perfis de praticantes, com provas de distâncias e modelos diferentes.

\section{DISCUSSÕES}

Quando analisamos a distribuição dos participantes por sexo (Gráfico 1), foi possível verificar uma redução da diferença no número de participantes, o sexo feminino ainda continua sendo minoria entre os corredores. Este fato também foi observado por outros pesquisadores. Rojo, Rocha e Nazario (2016), apresentam que em um evento de corrida de rua de $10 \mathrm{~km}$ realizado por uma prefeitura municipal a proporção dos participantes por sexo é de $32,04 \%$ de mulheres e $67,96 \%$ de homens.

A desproporção que tende a balança para uma maior participação masculina também é observada em corridas de percursos maiores, como no caso investigado em uma meia-maratona por Sierra et al (2015) e 
em maratonas, no estudo realizado por Moura, Palma, Costa Filho \& de Almeida (2010). Nesses casos a diferença chega a ser maior entre os sexos.

O cenário curitibano, também, já foi descrito anteriormente por outros pesquisadores. Purim, KappTitski, Barauce Bento y Leite (2014), aponta para um quadro em que a proporção de corredores é de 75,4\% do sexo masculino e $24,6 \%$ do sexo feminino. Tal fato corrobora com os dados encontrados em nossa pesquisa, mostrando que os corredores estão em maior número.

Nesse sentido, não encontramos nenhuma ação específica que possa ter contribuído para a redução da desproporcionalidade entre os gêneros dos praticantes da corrida de rua em Curitiba. Tal fato pode ser considerado como um movimento social que vem ocorrendo tanto em Curitiba quanto em outras regióes do Brasil, e não tem influência direta das ações da SMELJ.

Quando os dados foram analisados separadamente (sexo masculino e feminino) (Gráfico 2 e 3), dados muito próximos aos que encontramos foram observados por outros pesquisadores. Em pesquisa realizada por Rojo, et al. (2016), os autores apresentam que a faixa etária com maior representatividade, considerando ambos os sexos, em uma prova de $10 \mathrm{~km}$ é de 30 a 34 anos, entretanto quando considerado individualmente cada sexo, no masculino a faixa etária com maior participação é a de 35 a 39 anos, já a feminina permanece com a de 30 a 34 anos. Em ambos os casos é uma categoria abaixo das encontradas em nosso estudo. Porém, não é uma diferença significativa pois ambas possuem corredores de idades próximas.

Em estudos realizados com participantes de uma meia-maratona (Sierra et al, 2015) e com maratonistas (Moura et al, 2010), foram encontrados resultados semelhantes, tendo na faixa etária entre 30 e 50 anos o pico no volume de corredores. Na realidade curitibana, o estudo realizado por Purim et al (2014), apresenta uma mediana para a idade dos corredores de 38,4 anos de idade, sendo que a média para participantes do sexo masculino é de 38,9 anos e do feminino, 36,7 anos.

Como podemos observar nos resultados encontrados em nossos dados, e estes em diálogo com outras pesquisas realizadas, a idade dos corredores, por mais que seja diversa, apresenta grande predominância de indivíduos acima dos 30 anos. Tal fato nos mostra que a corrida de rua é uma modalidade cuja iniciação tem se dado tardiamente, e também se prolongado por idades mais avançadas, o que torna-se uma particularidade perante as demais modalidades. Este dado é evidenciado por uma pesquisa realizada pelo Centro de Referência de Qualidade de Vida e Movimento (CRQVM), que aponta que 70\% dos participantes nunca foram atletas e iniciaram-se na prática depois de adultos (Biscaia e Belinazzo, 2014a, b).

Quanto ao número de participantes cadeirantes ou com deficiência visual (Gráfico 4 e 5), a literatura acadêmica que versa sobre as corridas de rua, encontramos no estudo de Dallari (2009), uma realidade diferente ao existente em nossa pesquisa. Os dados apresentados pela autora, relativos aos eventos de corridas de rua do estado de São Paulo, evidenciam um crescimento significativo no número de participantes com algum tipo de deficiência. Segundo a autora, do total de participantes que no ano de 2002 eram de 31, em 2008 acumulou 323.

Como observamos por meio do diálogo com a pesquisa de Dallari, o cenário da participação de indivíduos com deficiência em Curitiba faz percurso contrário ao de outras localidades. Diante da conjuntura desfavorável em relação ao indivíduo com deficiência, observamos a ação realizada pelo CRQVM, já abordada no capítulo anterior, que busca capacitar corredores para atuar como atletas-guias. Esse cenário corrobora com uma preocupação em reverter o quadro e trazer novamente corredores com deficiência para a prática da modalidade.

No relato de experiência apresentado pela SMELJ, encontramos outros elementos importantes para compreender o perfil do corredor curitibano. Segundo o texto, $62 \%$ dos participantes começaram a correr depois de 2010 (Biscaia e Belinazzo, 2014b). Os autores da pesquisa apontam que nesse período ocorre o "boom" das corridas de rua em Curitiba.

Os motivos que os praticantes têm para a prática da modalidade é outro fator importante para se considerar na hora de discutir a respeito das formulações das políticas públicas para o esporte. Ao pensar 
o desenvolvimento das ações, leva-se em consideração a compreensão da polissemia do esporte, em que o praticante dá sentido à sua prática. Nesse caso, para a corrida de rua em Curitiba, segundo o mesmo levantamento, os corredores têm como motivo predominante a busca pela saúde (Biscaia e Belinazzo, 2014b).

Ao compararmos tais informações com a literatura publicada sobre o tema chegamos à conclusão de que os resultados são semelhantes. Balbinotti et al (2015), aponta que a dimensão da saúde é a que aparece com maior incidência nas respostas dos corredores. Em pesquisas realizadas com corredores curitibanos, não é diferente, Pereira, Assis e Navarro (2010) e Furlan (2014), também chegaram a resultados semelhantes, com a dimensão da saúde sendo o primeiro elemento motivador dos praticantes de corrida de rua.

Ao compararmos tal elemento motivador com a missão proposta pela SMELJ, observamos que nos últimos anos a secretaria tem valorizado a busca pelo estilo de vida saudável e a qualidade de vida do cidadão curitibano. Esse contexto nos permite a leitura de que os objetivos propostos pela entidade têm sido alcançados.

Por fim, mas não menos importante, consideramos para a análise a condição social dos corredores curitibanos. Segundo Biscaia e Belinazzo (2014b), uma grande parte dos corredores curitibanos possui formação em ensino superior completo. Essa composição do grupo de corredores de rua é apontada por Rojo (2014) como nova, sendo ela uma das transformações ocorridas no universo da modalidade.

Pazin et al (2008) apontam que naquele período 76,5\% dos corredores participantes de sua pesquisa tinham renda familiar mensal superior a três salários mínimos ${ }^{4}$ e $31 \%$ possua rendas superiores a 9 salários mínimos. Os autores ainda apresentam que naquele período, $40 \%$ dos indivíduos participantes da pesquisa possuíam ensino superior completo.

Em um estudo mais recente realizado com corredores curitibanos, Purim et al (2014) apresentam com maior detalhamento alguns aspectos sociais dos praticantes de corrida de rua. Os autores apresentam os seguintes resultados: a) $68,1 \%$ dos corredores possuem escolaridade correspondente ao ensino superior completo, ou formação complementar posterior; b) 74\% são indivíduos de cor de pele branca.

O receio apresentado na introdução do presente trabalho, a respeito de uma possível exclusão social de praticantes com condições sociais menos favorecidas da prática da corrida, retoma nesse momento, uma vez que os dados evidenciam que parcelas majoritárias dos praticantes possuem condições sociais melhores. Porém, ao observar as ações propostas pela SMELJ, vemos que projetos que promovem a prática da modalidade sem gerar custos ao cidadão são realizados, como é o caso das assessorias públicas e os circuitos de corridas.

Diante do presente cenário observamos que não é somente pela gratuidade das ações que teremos uma maior ampliação da participação popular, independente de sua condição social. Porém, em relação a possível exclusão social, pensamos ser um tema mais complexo sobre a permanência do agente no universo social da corrida de rua. Mesmo possuindo a leitura do papel importante do Estado intervindo para minimizar tal avanço, se fazem necessários, para a compreensão desse tema, estudos mais voltados ao campo sociológico.

As informações contidas nesse tópico nos permitem minimamente esboçar uma tentativa de leitura sobre o perfil do praticante de corrida de rua de Curitiba. Já salientando que, de acordo com os diálogos realizados com a produção acadêmica que discute cada ponto apresentado, esse cenário não difere em volumes significativos, ao encontrado em outras localidades. Os corredores curitibanos são, em sua predominância, indivíduos de idade média de 30 a 50 anos, em sua maioria do sexo masculino, com cor de pele branca, sem deficiência, com alta escolaridade, e se utiliza da prática da corrida de rua como meio para a busca da saúde.

Após traçar um perfil para o praticante da corrida de rua em Curitiba, no próximo tópico realizamos uma leitura da conjuntura dos eventos ocorridos na cidade.

Em relação as modalidades do calendário oficial de 2015 (Gráfico 6), foi possível verificar a corrida, ciclismo e caminhada com destaque. No que se refere às caminhadas, no entanto, vale salientar que apesar do número ser relativamente baixo, se comparado com os eventos de corrida de rua, essa soma corresponde apenas aos eventos exclusivos da modalidade. Com isso, é importante lembrar que, no gráfico, foram contabilizadas as 
modalidades centrais dos eventos. É frequente a realização de eventos de corrida de rua em que é agregada a prática da caminhada como um evento secundário, de modo a incentivar os participantes que iniciam nela, a posteriormente, dedicarem-se à prática da corrida de rua.

Ao tratarmos somente na corrida de rua, podemos visualizar a grande abrangência da modalidade. Como aponta o gráfico, os eventos de corrida de rua acontecem em grande volume na cidade de Curitiba. Para fim de visualização, ao fazermos um exercício de comparação, se ocorre na cidade de Curitiba 75 corridas, podemos afirmar que há uma média de mais de um evento por semana, ou seja, 1,4 eventos de corrida por semana. Isso ao levarmos em consideração que um ano possui aproximadamente 52 semanas.

Dentro dessa discussão vale considerarmos também outro fator, os dados apresentados são referentes apenas aos eventos que ocorrem sob regulamentação da SMELJ, ou seja, são contabilizadas apenas as corridas que ocorrem na cidade de Curitiba. Esse fato é de grande relevância se pensarmos que a região metropolitana de Curitiba possui um grande número de cidades e que uma grande parte também realiza e sedia eventos de corridas de rua, o que nos faz pensar que essa estrutura e números possam ser ainda maiores.

A importância da região metropolitana ao analisarmos os dados gerados pelo calendário se deve ao fato de que os habitantes e eventos podem influenciar a estrutura interna das corridas de rua em Curitiba, uma vez que, dada a proximidade dos municípios, é tanto possível quanto frequente, a participação de corredores de outros municípios nos eventos realizados em Curitiba, e o caminho inverso também é verdadeiro.

Quanto a distribuição de corridas por mês (Gráfico 7), foi possível verificar que os meses de janeiro e fevereiro são meses tidos como períodos de férias por grande parcela da sociedade (férias escolares, recessos, feriados). Devido a essa característica do período do ano, há uma possibilidade maior de êxodo dos moradores da cidade para outras regiões. Com isso, a procura pela realização dos eventos durante os dois primeiros meses do ano é menor. A baixa incidência de eventos nesse período, também foi observada por Hayek (2014), em seu estudo feito com as corridas de rua na cidade de São Paulo.

Porém, ao retirar esse período da análise, percebemos que a média de eventos que ocorrem nos outros meses, é de aproximadamente 7 eventos por mês, sendo que o mês de setembro tem o maior número de eventos registrados, 9 corridas, o que corresponde a $12 \%$ do total de corridas de rua do ano de Curitiba. $\mathrm{E}$ em dezembro 5 eventos, o que corresponde a 6,7\% do número de corridas do calendário. Para Hayek (2014), a concentração de maior volume de eventos em meses centrais do ano pode estar associada às condições favoráveis para a prática da modalidade, inclusive climáticas.

Quando apontamos os responsáveis pela organização das corridas de rua em Curitiba (Gráfico 8), foi encontrado cinco perfis de organizadores (Privada; Pública/SMELJ; SISTEMA S; JUS/POL/EX; PARCERIA PP), notando a predominância das corridas privadas. Os dados revelam que 51 eventos são realizados sob essa ótica, o que corresponde a $68 \%$ do total das corridas de rua realizadas. Ao levantar as características das organizadoras de eventos de corridas na cidade de São Paulo, Hayek (2014), apresenta um cenário próximo: $80 \%$ das corridas de rua são realizadas por organizadoras privadas, sendo que $68,7 \%$ das corridas aprovadas para a realização estão concentradas em um número de apenas 11 organizadoras.

O cenário encontrado em Curitiba, em nossa leitura, pode ser compreendido como fruto de duas intervenções diferentes, tanto oriunda da estrutura econômica quanto das organizações públicas, ou seja, produto de uma política pública. No que concerne à economia, levamos em consideração o aquecimento do mercado sobre o universo das corridas de rua, como já discutido aqui. Já referente a parte do poder público é preciso analisar a atuação da CAEEL na composição desse quadro, uma vez que é a referida comissão que avalia os eventos que serão realizados no município. Vale lembrar ainda que, com o incremento no número de eventos realizados por instituições privadas, houve a redução de eventos promovidos pelo poder público municipal.

Como vimos anteriormente, as corridas privadas podem possuir características relativas ao modelo de "corrida fashion", que é visto como um produto a ser vendido aos praticantes das corridas, sendo cobrados 
valores econômicos altos, e deixando os valores esportivos da modalidade por vezes em segundo plano (Oliveira, 2010).

\section{CONSIDERAÇÕES FINAIS}

A partir dos dados analisados, o estudo evidenciou a presença de corredores em todas as categorias por faixas etárias dispostas pelos eventos de corrida de rua realizados pela SMELJ. Fato que ocorre em ambos os sexos. A participação distribuída por sexo, mesmo com aumento do número de mulheres ainda tem maioria de corredores homens. Quando referente a categoria com maior número de participantes é observado os atletas com idade entre 35 a 44 anos. Constatou-se também, que durante o recorte temporal da pesquisa, houve a quedo do número de praticantes com algum tipo de deficiência.

As características apresentadas pelos corredores de Curitiba, expostas no presente estudo, permite nos propor que os corredores curitibanos são, em sua predominância, indivíduos de idade média de 30 a 50 anos, em sua maioria do sexo masculino, com cor de pele branca, sem deficiência, com alta escolaridade, e se utiliza da prática da corrida de rua como meio para a busca da saúde.

Já com relação ao perfil dos eventos de corrida de rua realizados em Curitiba, foi diagnosticado que as corridas de rua predominam o calendário anual proposto e regulado pela SMELJ. Observamos também que as corridas de rua estão distribuídas durante todos os meses do ano, com maiores números de eventos entre os meses de março a novembro. As organizações desses eventos, são predominantemente realizadas por instituições privadas.

Concluímos, que os dados encontrados nesse estudo, apontam para características semelhantes as expostas por pesquisas anteriores (Rojo et al., 2017; Rojo, et al., 2016; Oliveira, 2010), que sugerem a corrida de rua como sendo uma modalidade com praticantes com melhores condições financeiras e eventos denominados como corridas fashion.

\section{REFERÊNCIAS}

Balbinotti, M. A. A., Gonçalves, G. H. T., Klering, R. T., Wiethaeuper, D., \& Balbinotti, C. A. A. (2015). Perfis motivacionais de corredores de rua com diferentes tempos de prática. Revista Brasileira de Ciências do Esporte, $37(1), 65-73$.

Biscaia, L. R. R., Belinazzo, L. O. B. (2014a). Corridas de rua Smelj-estadistica 2008/2014: mostra de experiências 20122013-2014 (pp. 181-182). Curitiba: Imap. b.

Biscaia, L. R. R., Belinazzo, L. O. B. (2014b). Perfil dos corredores de rua de curitiva. In E.F. Mathoso (Org.). “Acontece na smelj": mostra de experiências 2012 - 2013 - 2014 (pp. 181-182) Curitiba: Imap. a.

Dallari, M. M. (2009). Corrida de rua: um fenômeno sociocultural contemporâneo (Tese de doutorado). Universidade de São Paulo, USP, São Paulo, SP.

Furlan, A. (2014). Fatores Motivacionais Relacionados à Prática de Corrida de Rua por Mulheres Adultas na Cidade de Curitiba/PR. Monografia de Graduação (Bacharelado em Educação Física). Departamento Acadêmico de Educação Física, Universidade Tecnológica Federal do Paraná, Curitiba.

Hayek, F. B. A. (2014). Gestão do Trânsito para Atividades Esportivas na Via-Corridas de Rua na cidade de São Paulo. Podium Sport, Leisure and Tourism Review, 3(3), 45-56.

Moraes e Silva, M. (2011). Novos modos de olhar outras maneiras de se comportar: a emergência do dispositivo esportivo da cidade de Curitiba (1899-1918) (Tese Doutorado em Educação). Faculdade de Educação, Universidade Estadual de Campinas, Campinas.

Moura, C. A., Palma, A., Costa Filho, P. N., \& de Almeida, M. N. (2010). Características associadas aos corredores da maratona do Rio de Janeiro. Fitness \& Performance Journal, 9(1), 106-112. 
Oliveira, S. N. D. (2010). Lazer sério e envelhecimento: loucos por corrida (Dissertação de mestrado). Universidade Federal do Rio Grande do Sul, Porto Alegre, RS.

Pazin, J. et al. (2008). Corredores de rua: características demográficas, treinamento e prevalência de lesões. Rev Bras cineantropom desempenho bum, 10(3), 277-82.

Pereira, E. R.; Assis, F. R.; Navarro, F. (2012). Perfil e hábitos de hidratação dos corredores de rua de Curitiba, categoria amador. RBNE-Revista Brasileira de Nutrição Esportiva, 4(22), 336-344.

Purim, K. S., KappTitski, A. C., Barauce Bento, P. C. \& Leite, N. (2014). Lesões desportivas e cutâneas em adeptos de corrida de rua. Rev. bras. med. esporte, 20(4), 299-303.

Rojo, J. R., Starepravo F. A., Canan F., Mezzadri F. M., Silva M. M. (2017). Transformações no modelo de corridas de rua no Brasil: um estudo na Prova Rústica Tiradentes. R. bras. Ci. e Mov., 25(1), 19-28.

Rojo, J. R. (2014). Processo de transformação das corridas de rua: um estudo sobre a prova rústica tiradentes (Monografia de graduação). Universidade Estadual de Maringá, Maringá, PR.

Rojo, J. R., Ferreira da Rocha, F., y Nazario, P. K. (2016). Caracteristicas dos corredores de rua: um mapeamento dos participantes da $41^{\text {a }}$ Prova Rústica Tiradentes. Educación Física y Ciencia, 18(1), e008.Recuperado de http://w ww.efyc.fahce.unlp.edu.ar/article/view/EFyCv18n01a08/

Sierra, A. P., Benetti, M., Ghorayeb, N., Sierra, C., da Cunha Bastos, F., Rocco Junior, A. y Peduti Dal Molin Kiss, M.A. (2015). Analysis of Participation and Performance in Half Marathon Runners. Journal of Sports Science, 3(1), 96-104.

\section{Notas}

1 Calendario oficial - Corridas de rua, ciclismo caminhada 2015. Disponível em: http://www.curitiba.pr.gov.br/conteu do/calendario-oficial-corridas-de-rua-ciclismo-e-caminhada-2015/2103 acesso em 11/12/2015.

2 Os números contidos no gráfico, referem-se à soma de todas as etapas do circuito de corridas de rua adulto realizadas em cada ano. Portanto não se tem como objetivo, nesse momento, analisar o incremento ou diminuição do número de participantes, pois o número de etapas varia de um ano a outro. A intenção final desses dados é apresentar a proporção entre participação por sexo.

3 Circuito realizado pelo SESI, em que são realizadas diversas etapas, tanto na cidade de Curitiba, como em outros municípios da região metropolitana.

4 Segundo os autores, no período da realização do estudo o salário mínimo correspondia a 380,00 reais. 